\title{
Effects of consumption of ethanol on the biological monitoring of exposure to organic solvent vapours: a simulation study with trichloroethylene
}

\author{
A Sato, K Endoh, T Kaneko, G Johanson
}

\begin{abstract}
This study illustrates possible influences of consumption of ethanol on the pharmacokinetic behaviour of inhaled trichloroethylene (TRI) in relation to biological monitoring of exposure. The results were obtained for a standard male worker of $70 \mathrm{~kg}$ by physiologically based pharmacokinetic modelling. Depending on the pattern of consumption of ethanol, enzyme inhibition or induction was assumed to prevail in this worker. The inhibition and induction were modelled by assuming competitive metabolic interaction between TRI and ethanol and increased maximum velocity ( $V \max )$ of TRI metabolism respectively. Ingestion of moderate amounts of ethanol before the start of work or at lunch time, but not at the end of work, caused pronounced increases in blood TRI concentrations and decreases in the urinary excretion rates of TRI metabolites, this effect lasting until the next day. The effects were smaller the higher the exposure concentration of TRI. Induction of TRI metabolism, supposedly by consumption of ethanol the previous evening, caused only small changes in the pharmacokinetic profile at $50 \mathrm{ppm}$, but appreciable changes at $500 \mathrm{ppm}$.
\end{abstract}

Biological monitoring of exposure is a measure of the amount of chemical absorbed into the body and is performed by measuring the amount of chemical or its metabolites in biological samples. Any environmental factor which influences the absorption, distribution, metabolism, or elimination of a chemical can affect the result of exposure monitoring.

Department of Environmental Health, Medical University of Yamanashi, Tamaho, Yamanashi, 40938 Japan

A Sato, K Endoh, T Kaneko

Division of Work and Environmental Physiology,

National Institute of Occupational Health, S-171 84

Solna and Department of Occupational Medicine,

University Hospital, S-751 85 Uppsala, Sweden

G Johanson
The metabolism of organic solvents is important from two aspects. ${ }^{1}$ Firstly, metabolism is the major factor responsible for the disappearance of solvents from the body. Thus a change in the metabolism may alter their pharmacokinetic behaviour and consequently affect the results of biological monitoring of exposure to solvents. Secondly, biotransformation sometimes results in the production of highly reactive intermediates that can bind covalently to critical components of the target cell. Such bioactivation is responsible for some health hazards caused by environmental chemicals including trichloroethylene (TRI) induced hepatotoxicity.

Enzymes regulating the biotransformation are cytochrome P-450 related mono-oxygenases, which are found at the highest concentration in the liver. ${ }^{1}$ The metabolic pathway whereby the cytochrome $\mathrm{P}-450$ system is involved is considered to be a rate limiting step in the overall metabolic processes. This enzyme system is known to be susceptible to the influence of various environmental factors including nutritional state, medicines, and exposure to environmental chemicals.

Consumption of alcohol is probably one of the most important environmental factors that affect the metabolism of organic solvents, as ethanol is the only biologically active substance that many people, including those who are occupationally exposed to organic solvents, frequently consume in multigram quantities. Some industrial workers may drink large quantities of alcoholic beverages in the evening and are then exposed to organic solvent vapours at work the next day. Others may drink during work time or at lunch time. It is likely, therefore, that drinking ethanol produces a profound influence on the biological monitoring of exposure to organic solvents.

Ethanol has opposite effects on the metabolism of organic solvents; enzyme inhibition and enzyme induction. ${ }^{1}$ The time elapsed after consumption of alcohol determines which of the effects will dominate. During and shortly after drinking, ethanol is present at high concentrations in the body and acts as an inhibitor. Later, the ethanol concentration is reduced and the stimulatory effect outweighs the inhibitory effect. 
This report discusses possible effects of consumption of ethanol on the pharmacokinetic behaviour of TRI in relation to the biological monitoring of exposure by using a computer assisted physiological simulation model.

\section{Methods}

SIMULATION MODEL

Our pharmacokinetic simulation model for TRI has been detailed elsewhere. ${ }^{2}$ Briefly, the model is composed of seven physiological compartments for TRI and three more compartments for its metabolites, chloral hydrate $(\mathrm{CH})$, trichloroethanol (TCE), and trichloroacetic acid (TCA).

It was assumed that the metabolic conversion of TRI to $\mathrm{CH}$ occurs only in the hepatic compartment according to a Michaelis-Menten type of metabolism. The metabolic constants reported by Koizumi, ${ }^{3}$ a maximum velocity (Vmax) of $3.2 \mathrm{mg} / \mathrm{min}$ and a Michaelis constant $(\mathrm{Km})$ of $2.5 \mathrm{mg} / 1$ for a standard male worker of $70 \mathrm{~kg}$, were used for simulation of TRI kinetics under normal conditions. Rate constants for the metabolic conversion of $\mathrm{CH}$ to TCE and TCA and for the urinary excretion of TCE and TCA were from Fernandez et al. ${ }^{4}$

Mass balance of TRI was performed on each compartment, and its transfer throughout the system was expressed in the form of simultaneous differential equations, which were then solved numerically with a personal computer (Macintosh SE/30). ${ }^{2}$ The simulation parameters used have been described elsewhere. ${ }^{25}$

\section{MODELLING OF METABOLISM INHIBITION}

Ingested ethanol was assumed to directly enter the gastrointestinal compartment according to the first order absorption rate constant $\left(0.03 \mathrm{~min}^{-1}\right)$ that was determined by fitting the ethanol concentration in blood to the experimental data of Wallén et al. ${ }^{6}$ The blood/air partition coefficient of ethanol was taken as 2000 (values between 1265 and 2516 have been reported by Fiserova-Bergerova and $\mathrm{Diaz}^{7}$ ) and the tissue/blood partition coefficient for tissue of every compartment was assumed to be unity. The elimination of ethanol was assumed to occur from the hepatic compartment according to zero order kinetics with a rate constant of $3 \mathrm{mmol} / \mathrm{min}$ (corresponding to $\left.120 \mathrm{mg} / \mathrm{kg} / \mathrm{h}^{8}\right)$. Pharmacodynamic effects of ethanol ingestion, such as changes in hepatic blood flow, were disregarded in the present study for the sake of simplicity.

According to the experimental findings of Sato et $a l,{ }^{9}$ competitive metabolic interaction between ethanol and TRI was assumed. It was further assumed that ethanol interferes with only the first, rate limiting step of TRI metabolism-that is, the conversion of TRI to $\mathrm{CH}$, which is catalysed by cytochrome P-450.
These assumptions enabled us to express the rate of TRI metabolism (v) under the influence of acutely ingested ethanol by the equation:

$$
\mathbf{v}=\mathrm{Vmax} \cdot \mathrm{C}_{\mathrm{H}} /\left[\mathrm{Km}+(\mathrm{Km} / \mathrm{Ki}) \cdot \mathbf{I}+\mathrm{C}_{\mathrm{H}}\right]
$$

where $C_{H}$ and I denote the concentrations of TRI and ethanol in the hepatic compartment (HC) respectively and $\mathrm{Ki}$ the inhibition constant of ethanol toward TRI metabolism.

Hence, the change in TRI amount over time in the hepatic compartment $\left(\mathrm{dX}_{\mathrm{H}} / \mathrm{dt}\right)$ was described by the equation:

$$
\begin{gathered}
\mathrm{dX}_{\mathrm{H}} / \mathrm{dt}=\mathrm{Q}_{\mathrm{H}} \cdot \lambda \cdot \mathrm{C}_{\mathrm{L}}+\mathrm{Q}_{\mathrm{G}} \cdot \mathrm{C}_{\mathrm{G}} / \mathrm{L}_{\mathrm{G}}-\left(\mathrm{Q}_{\mathrm{G}}+\mathrm{Q}_{\mathrm{H}}\right) \cdot \mathrm{C}_{\mathrm{H}} / \mathrm{L}_{\mathrm{H}} \\
-\mathrm{Vmax} \cdot \mathrm{C}_{\mathrm{H}} /\left[\mathrm{Km}+(\mathrm{Km} / \mathrm{Ki}) \cdot \mathrm{I}+\mathrm{C}_{\mathrm{H}}\right],
\end{gathered}
$$

where $\mathrm{Q}$ denotes the blood flow, $\mathrm{C}$ the TRI concentration, and $\mathrm{L}$ the tissue/blood partition coefficient of TRI. The subscripts ${ }_{H}{ }_{L}$, and ${ }_{G}$ correspond to the hepatic, lung, and gastrointestinal compartments. The symbol $\lambda$ denotes the blood/air partition coefficient of TRI. A Ki value of $0.42 \mathrm{mM}$ reported by Sato $e t a l^{9}$ was employed in the simulation.

\section{MODELLING OF ENZYME INDUCTION}

Enzyme induction was simulated by increasing the Vmax of TRI metabolism without changing the $\mathrm{Km}$ according to the report of Nakajima et al. ${ }^{10}$ These simulations were designed to illustrate the induction effect of ethanol consumed in the evening before the work shift with exposure to TRI. Such rapid induction of TRI metabolism has been seen in rats given ethanol. ${ }^{9}$

Again, it was assumed that the consumption of ethanol would affect only the rate limiting step of TRI metabolism - that is, the pathway from TRI to CH. This assumption is considered further in the Discussion section.

\section{EXPOSURE SCHEDULE}

In all simulations, a $70 \mathrm{~kg}$ man was assumed to inhale air containing TRI at various concentrations during a work day of eight hours from 8.00 to 17.00 with a one hour lunch break between 12.00 and 13.00 and the TRI concentration in the blood and the urinary excretion rates of total trichlorocompounds (TTC = TCA + TCE) was computed during and after the exposure. To study the inhibitory effect of ethanol, a 15 minute oral ingestion of various amounts of ethanol before the start of work (07.45), at the end of the morning shift (12.00), or at the end of the afternoon shift (17.00) was simulated.

\section{Results}

INHIBITION OF METABOLISM

Ingestion of a moderate dose of ethanol (5-20 mmol/ $\mathrm{kg} ; 0.23-0.92 \mathrm{~g} / \mathrm{kg}$ ) before the start of work or at lunch time caused a considerable alteration in TRI kinetics (figs 1 and 2). After ethanol ingestion at a dose 
of $20 \mathrm{mmol} / \mathrm{kg}$ the blood TRI concentration was increased by about $70 \%$ (fig $1 \mathrm{~A}$ and $\mathrm{B}$ ) and the urinary excretion rate of TTC decreased by about
$40 \%$ (fig $2 \mathrm{~A}$ and $\mathrm{B}$ ). The effect on the TTC excretion lasted until the start of the next shift. On the other hand, ethanol ingested at the end of work caused only

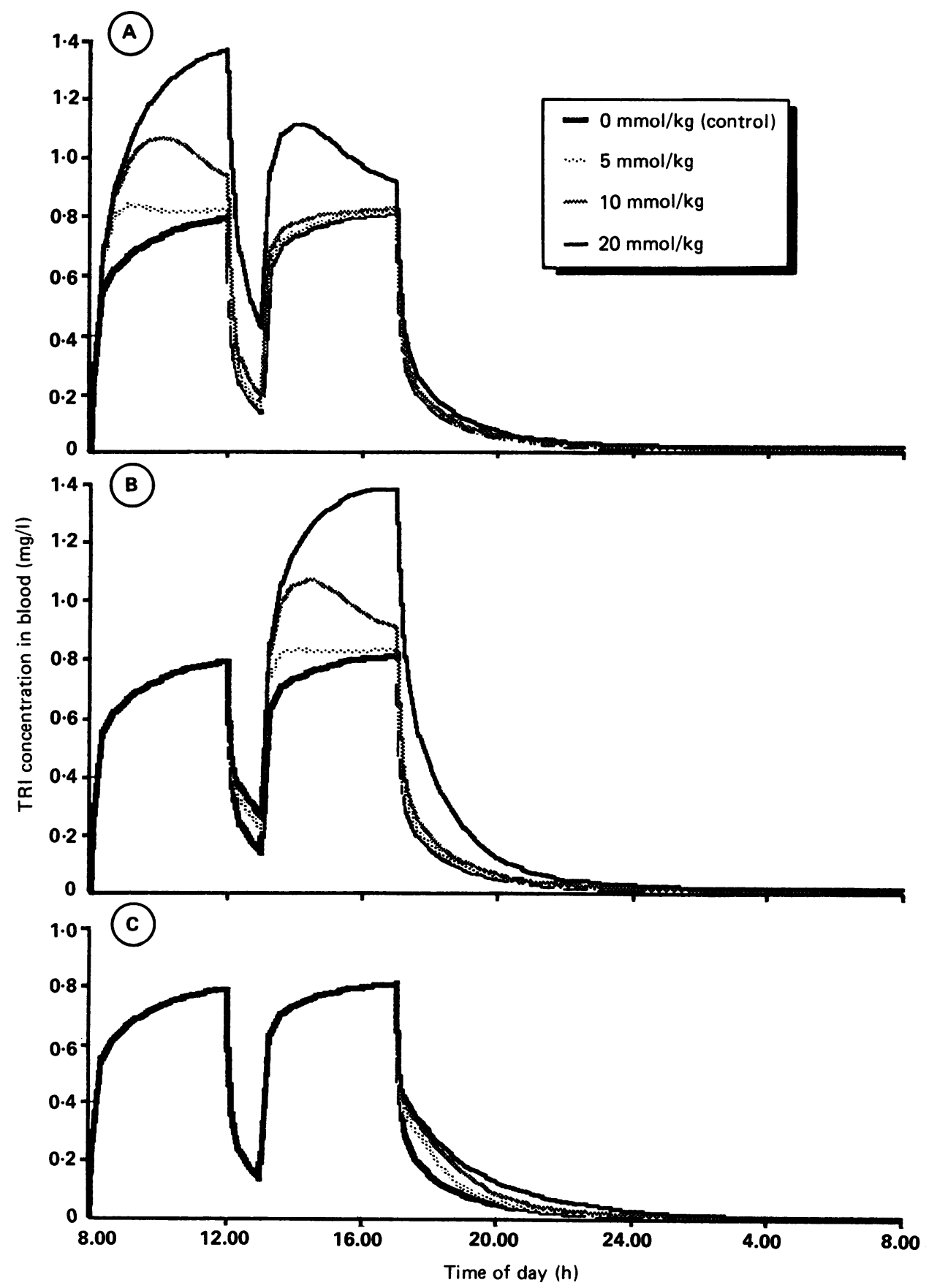

Figure 1 Effects of ethanol on the TRI concentration in blood. Simulations were performed for a standard male worker $(70 \mathrm{~kg})$ who inhaled $50 \mathrm{ppm}$ of TRI for eight hours (08.00-12.00 and 13.00-17.00) and consumed ethanol $(0,5,10$, or $20 \mathrm{mmol} / \mathrm{kg}$ ) in 15 minutes before the start of work (07.45) (A), at the lunch break (12.00) (B), or immediately after the end of work (17.00) (C). 

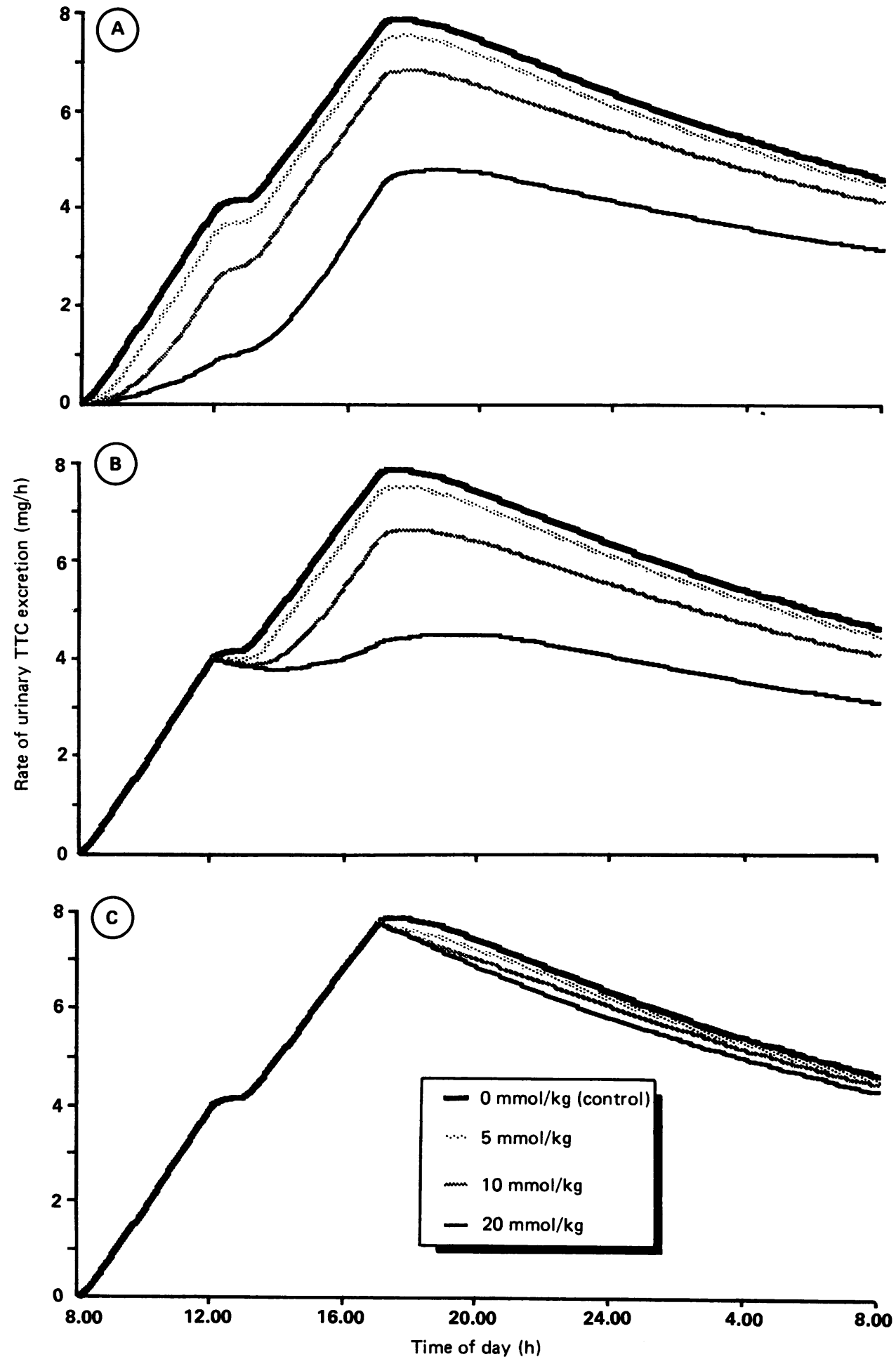

Figure 2 Effects of ethanol on the urinary excretion of TRI metabolites (TTC). The TRI and ethanol exposure conditions are given in figure 1 . 
a marginal effect on the pharmacokinetic behaviour of TRI (figs $1 \mathrm{C}$ and 2C).

Figure 3 depicts the dose dependent metabolic interaction between ethanol and TRI in a different way. The area under the blood TRI concentration time curve for 24 hours $(8.00-8.00)$ and the area under the TTC excretion time curve (corresponding to cumulative amounts of TTC in the urine) for the same period of time are shown. In these simulations, the standard worker inhaled air containing TRI at various concentrations $(0-2000 \mathrm{ppm})$ after having drunk various amounts of ethanol $(0-60 \mathrm{mmol} / \mathrm{kg})$ before the start of work (07.45). As the metabolic interaction between ethanol and TRI was assumed to be competitive, the larger the amount of ethanol, the more profound the inhibitory effect. By contrast with
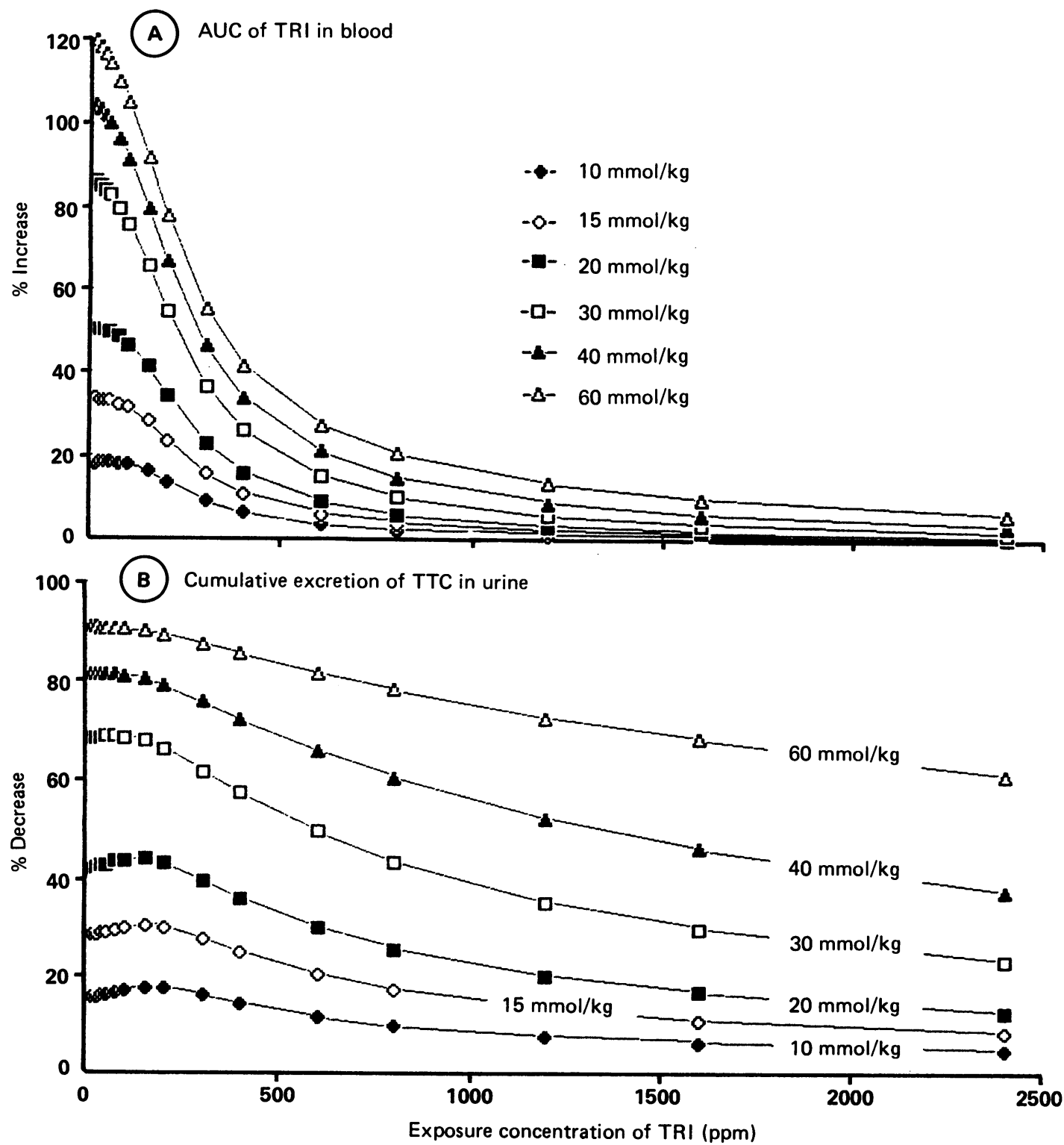

Figure 3 Dose dependent metabolic interaction between ethanol and TRI. A standard male worker inhaling air containing $T R I$ vapour at various concentrations $(0-2000 \mathrm{ppm})$ was assumed to consume various amounts of ethanol (0-60 mmol/kg) before the start of work (07.45). The inhibitory effect of ethanol is expressed as a per cent decrease in the area under the TRI concentration time curve (AUC of TRI in blood) $(A)$ and as a per cent increase in the area under the TTC excretion time curve (cumulative excretion of TTC in urine) (B) in comparison with those under a normal ethanol free condition respectively. 
the effect of enzyme induction (see next section), the metabolic interaction was particularly noted at a low level of TRI exposure (100 ppm or lower). The reason why the inhibition of metabolism does not influence the concentration of TRI in blood substantially at high exposure concentrations is that TRI metabolism becomes saturated and hence the contribution of metabolism to total TRI clearance from the body is only fractional at high exposure concentrations.
ENZYME INDUCTION

The effect of enzyme induction on TRI kinetics was dependent on the exposure level. A fivefold enhancement of TRI metabolism (Vmax was increased from 3.2 to $16 \mathrm{mg} / \mathrm{min}$ ) produced only a small effect at $50 \mathrm{ppm}$; the TRI concentration in blood decreased by only about $10 \%$, and the urinary TTC excretion increased by less than $10 \%$ (fig $4 \mathrm{~B}$ ). At $500 \mathrm{ppm}$, however, the TRI concentration was reduced by almost $50 \%$ and the rate of urinary TTC excretion

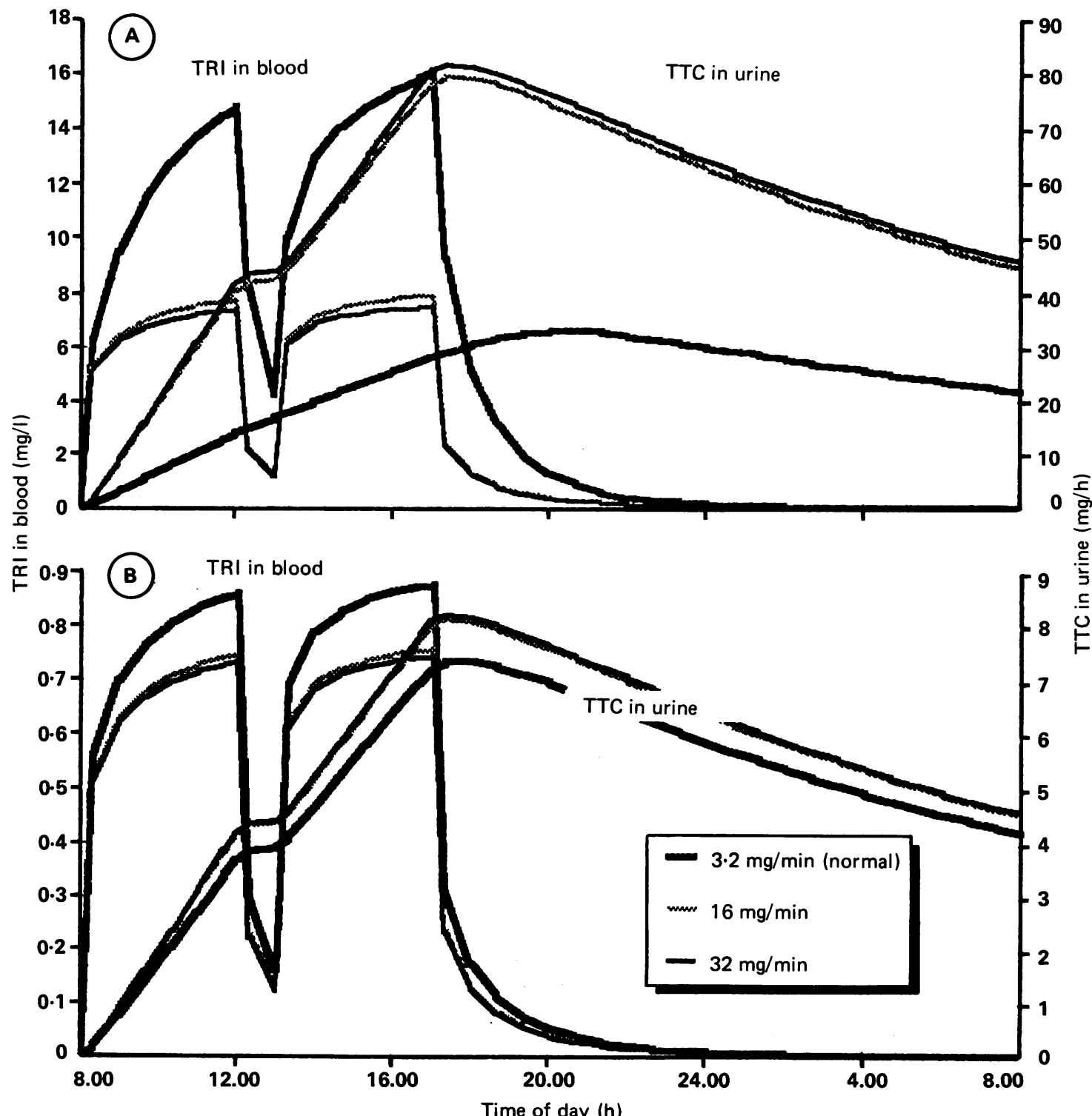

Figure 4 Effects of enzyme induction on the pharmacokinetic behaviour of TRI. Enzyme induction by ethanol was assumed to increase the Vmax of TRI metabolism five or 10-fold (from 3.2 to 16 or $32 \mathrm{mg} / \mathrm{min}$ ) without changing the Km. Simulations were performed for a standard male worker who inhaled $500(A)$ or $50 \mathrm{ppm}(B)$ of TRI for eight hours $(08.00-12.00$ and 13.00-17.00). The time courses of TRI concentration in blood and urinary TTC excretion are shown. 
was almost doubled (fig 4A). A further increase of Vmax from 16 to $32 \mathrm{mg} / \mathrm{min}$ (from a five to 10 -fold increase) produced only a marginal influence on the kinetic profiles at these exposure concentrations, a finding which suggests that TRI metabolism is not limited by the intrinsic capacity of the enzymes.

Figure 5 summarises the dose related effects of enzyme induction. The TRI concentration in blood and the rate of urinary TTC excretion both at the end of inhalation (17.00) are plotted against the concentration in inhaled air. When TRI exposure concentration was below $100 \mathrm{ppm}$, the effect was negligible. The higher the exposure concentration, the greater the influence of enzyme induction. When the concentration was $2000 \mathrm{ppm}$, the rate of urinary TTC excretion, an indicator of TRI metabolism in vivo, increased almost in coordination with the change in Vmax value. For example, a fivefold increase in Vmax
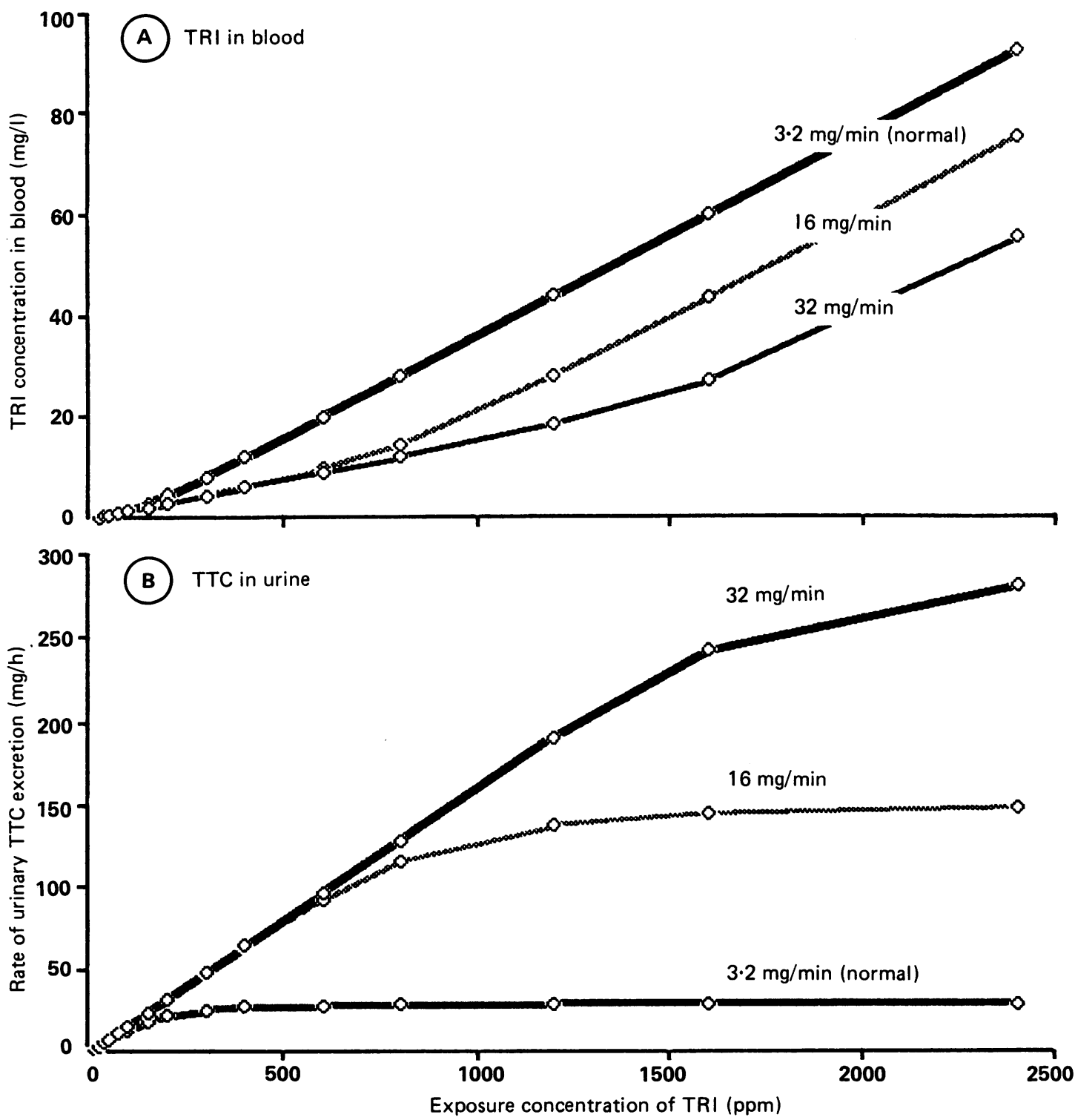

Figure 5 Dose dependent relation between enzyme induction and TRI metabolism. Enzyme induction by ethanol was assumed to increase the Vmax of TRI metabolism five $(16 \mathrm{mg} / \mathrm{min})$ or $10-f o l d ~(32 \mathrm{mg} / \mathrm{min})$ without changing the Km. Simulations were performed for a standard male worker who inhaled TRI at various concentrations (0-2000 ppm) for eight hours (08.0012.00 and 13.00-17.00) under the influence of enzyme induction. The TRI concentration in blood $(A)$ and the rate of urinary $T T C$ excretion $(B)$ at the end of inhalation (17.00) are plotted against the concentration in inhaled air. 
resulted in an almost fivefold increase in concentration of urinary metabolites at this exposure level. These results suggest that a shift from perfusion to capacity limited metabolism occurs as the exposure concentration increases and that under the influence of enzyme induction this shift occurs at a higher concentration.

\section{Discussion}

Ethanol induced inhibition of organic solvent metabolism is an established phenomenon. It has been shown in man that ethanol inhibits the metabolism of several organic solvents such as TRI, ${ }^{11}$ toluene, ${ }^{61213}$ xylenes, ${ }^{14}$ styrene, ${ }^{15}$ and methyl ethyl ketone. ${ }^{16}$

Generally, ethanol is a relatively weak inhibitor of the cytochrome P-450 dependent enzymes ( $\mathrm{Ki}>\mathrm{Km}$ in equation 1$).^{9}$ Ethanol is often present in the body in much higher concentrations than organic solvents, however $\left(\mathrm{I}>\mathrm{C}_{\mathrm{H}}\right)$, and is therefore expected to non-specifically inhibit the metabolism of various organic solvents.

Ethanol can interfere with the metabolism of other foreign chemicals at several steps, not only at the rate limiting step catalysed by cytochrome $P-450$ but also at subsequent pathways involving, for example, alcohol or aldehyde dehydrogenases. According to the study of Müller et $a l^{11}$ in which volunteers inhaled a constant concentration of $50 \mathrm{ppm}$ TRI for six hours, ethanol ingestion before and during the exposure (the concentration of ethanol in blood was maintained at $13 \mathrm{mM}$ on average during the exposure) almost completely inhibited the metabolic conversion of TRI to TCA. The reason may be that both the metabolic pathway of $\mathrm{CH}$ to TCA, which is supposed to be mediated by $\mathrm{CH}$ dehydrogenase requiring $\mathrm{NAD},{ }^{17}$ and the pathway of TCE to TCA, which is catalysed by cytochrome $\mathrm{P}-450,{ }^{11}$ are suppressed by the presence of ethanol. A similar result has also been reported with styrene metabolism by Wilson et al $^{15}$; ethanol inhibited the oxidation pathway from styrene glycol to mandelic acid. Because no quantitative data were available, however, regarding metabolic interactions at the intermediate pathways, only the interaction at the rate limiting pathway was included in our present simulation study.

Experimental evidence has shown that administration of ethanol to rats acutely ${ }^{9}$ or chronically ${ }^{18}$ accelerates the hepatic metabolism in vitro of various volatile hydrocarbons. The induction of a unique form of cytochrome P-450, P-450IIE $1^{19}$ by ethanol is responsible, at least in part, for this enhancement of metabolism. This isozyme, which has been referred to as $\mathrm{P}-450 \mathrm{ac}^{20}$ or $\mathrm{P}-450 \mathrm{j},{ }^{21}$ has a specifically high affinity for volatile, low molecular weight substances represented by organic solvents. ${ }^{22}$

It is certain that consumption of alcohol can alter the metabolism of organic solvents in animals: a single dose of ethanol drunk the day before exposure to TRI enhanced the TRI metabolism in vivo as shown by a faster disappearance of TRI from the blood as well as an increased urinary excretion of TRI metabolites. ${ }^{9}$ Similar results have also been reported with toluene. ${ }^{18}$ In these experiments, however, rats were exposed to TRI or toluene at a concentration as high as $500 \mathrm{ppm}$. Such high concentrations are rare in the work environment. The results of animal experiments in which extremely high concentrations were employed should be interpreted with caution in the light of the present study.

There are few observations as to whether the enzyme induction following consumption of ethanol has any significant effect on the pharmacokinetic behaviour of organic solvents in man. One report that suggests such an effect is that of Waldron et $a l^{12}$ showing that the concentrations of toluene in blood of workers exposed to toluene in a factory making rubber based products were lowest in those who drank regularly.

The extent of hepatic metabolism of chemical substances in vivo is determined by the relation between the metabolic clearance expressed in terms of $\mathrm{Vmax} /\left(\mathrm{Km}+\mathrm{C}_{\mathrm{H}}\right)$ and the hepatic blood flow..$^{23}$ When $V \max /\left(\mathrm{Km}+\mathrm{C}_{\mathrm{H}}\right)$ is larger than hepatic blood flow, the blood flow rate limits the metabolism (perfusion limited metabolism). Conversely, when $\mathrm{Vmax} /\left(\mathrm{Km}+\mathrm{C}_{\mathrm{H}}\right)$ is smaller than hepatic blood flow, the enzyme capacity is the rate limiting factor (capacity limited metabolism). Therefore, the hepatic metabolism in vivo at low dose exposures $\left(\mathrm{C}_{\mathrm{H}}\right.$ is small) can often be rate limited by the hepatic blood flow. This may be especially true with the metabolism under the influence of enzyme induction (Vmax is large).

The effect of enzyme induction on TRI metabolism in vivo thus depends on the exposure concentration (fig 5). At low exposure concentrations where the hepatic blood flow rate limits the metabolism, a fivefold increase in Vmax caused only a marginal influence on the TRI metabolism (fig 4). Such a small effect of an appreciable enzyme induction can be explained by the similarity in values of hepatic blood flow $(1.41 / \mathrm{min})$ and intrinsic metabolic clearance $(\mathrm{Vmax} / \mathrm{Km}=1.31 / \mathrm{min})$ in our model $(10 \%$ difference). The enzyme induction was not fully reflected in the metabolism in vivo until the exposure concentration reached $1000 \mathrm{ppm}$ or higher. In view of biological monitoring of exposure it is noteworthy that enzyme induction due to drinking ethanol may not affect the pharmacokinetic behaviour of organic solvents as much as animal studies conducted in vivo and in vitro suggest.

Requests for reprints to: Dr Akio Sato, Department of Environmental Health, Medical University of Yamanashi, Tamaho, Yamanashi, 409-38 Japan. 
1 Sato A, Nakajima T. Pharmacokinetics of organic solvent vapors in relation to their toxicity. Scand J Work Environ Health 1987;13:81-93.

2 Endoh K, Kaneko T, Sato A. A physiologically based pharmacokinetic model to describe the transfer of organic solvents in a human body-simulation of kinetic behavior of trichloroethylene using a spread sheet program. Japanese Journal of Industrial Health 1989;31:335-41.

3 Koizumi A. Potential of physiologically based pharmacokinetics to amalgamate kinetic data of trichloroethylene and tetrachloroethylene obtained in rats and man. Br J Ind Med 1989;46:239-49.

4 Fernandez JG, Droz PO, Humbert BE, Caperos JR. Trichloroethylene exposure. Simulation of uptake, excretion, and metabolism using a mathematical model. Br J Ind Med 1977;34:43-55.

5 Sato A, Endoh K, Kaneko T, Johanson G. A simulation study of physiological factors affecting pharmacokinetic behaviour of organic solvent vapours. Br J Ind Med 1991;48:342-7.

6 Wallén M,Näslund PH, Nordqvist MB. The effects of ethanol on the kinetics of toluene in man. Toxicol Appl Pharmacol 1984;76:414-9.

7 Fiserova-Bergerova V, Diaz ML. Determination and prediction of tissue-gas partition coefficients. Int Arch Occup Environ Health 1986;58:75-87.

8 Westerfeld WW, Schulman MP, Syracuse NY. Metabolism and caloric value of alcohol. JAMA 1959;170:197-203.

9 Sato A, Nakajima T, Koyama Y. Dose-related effects of a single dose of ethanol on the metabolism in rat liver of some aromatic and chlorinated hydrocarbons. Toxicol Appl Pharmacol 1981;60:8-15.

10 Nakajima T, Wang R-S, Murayama N, Sato A. Three forms of trichloroethylene-metabolizing enzymes in rat liver induced by ethanol, phenobarbital, and 3-methylcholanthrene. Toxicol Appl Pharmacol 1990;102:546-52.

11 Müller G, Spassowski M, Henschler D. Metabolism of trichloroethylene in man. III. Interaction of trichloroethylene and ethanol. Arch Toxicol 1975;33:173-89.

12 Waldron HA, Cherry N, Johnston JD. The effects of ethanol on blood toluene concentrations. Int Arch Occup Environ Health
1983;51:365-9.

13 Døssing M, Baelum J, Hansen SH, Lundqvist GR. Effect of ethanol, cimetidine and propranolol on toluene metabolism in man. Int Arch Occup Environ Health 1984;54:309-15.

14 Riihimäki V, Savolainen K, Pfäfli P, Sippel HW, Laine A Metabolic interaction between m-xylene and ethanol. Arch Toxicol 1982;49:253-63.

15 Wilson HK, Robertson SM, Waldron HA, Gompertz D. Effect of alcohol on the kinetics of mandelic acid excretion in volunteers exposed to styrene vapour. Br J Ind Med 1983;40:75-80.

16 Liira J, Riihimäki V, Engström K. Effects of ethanol on the kinetics of methyl ethyl ketone in man. Br J Ind Med 1990;47: $324-30$

17 Cooper JR, Friedman PJ. The enzymic oxidation of chloral hydrate to trichloroacetic acid. Biochem Pharmacol 1958;1: $76-82$.

18 Sato A, Nakajima T, Koyama Y. Effects of chronic ethanol consumption on hepatic metabolism of aromatic and chlorinated hydrocarbons in rats. $B r J$ Ind Med 1980;37:382-6.

19 Nebert DW, Adesnik M, Coon MJ, et al. The P450 gene superfamily: Recommended nomenclature. DNA 1987;6: $1-11$.

20 Patten CJ, Ning SM, Lu AYH, Yang CS. Acetone-inducible cytochrome P-450: Purification, catalytic activity, and interaction with cytochrome $b_{5}$. Arch Biochem Biophys 1986;251: 629-38.

21 Ryan DE, Ramanthan L, Iida S, et al. Characterization of a major form of rat hepatic microsomal cytochrome P-450 induced by isoniazid. J Biol Chem 1985;260:6385-93.

22 Sato A, Nakajima T. Enhanced metabolism of volatile hydrocarbons in rat liver following food deprivation, restricted carbohydrate intake and administration of ethanol, phenobarbital, polychlorinated biphenyl and 3-methylcholanthrene: a comparative study. Xenobiotica 1985;15:67-75.

23 Hoyumpa AM Jr, Schenker S. Major drug interactions: effect of liver disease, alcohol, and malnutrition. Ann Rev Med 1982; 33:113-49.

Accepted 17 December 1990 